\title{
Seroprevalence of syphilis antibodies among blood donors at North Darfur State-Sudan, from 2017 to 2019
}

\begin{abstract}
Background: syphilis is one of the infections transmitted through blood transfusion as shown by high antibodies detection in healthy African blood. Syphilis prevalence among blood donors in sub-Saharan African countries varies among people; In Nigeria, Mali, Tanzania, and Kenya the prevalence was $3.1 \%, 0.3 \%, 12.8 \%$, and $3.8 \%$ respectively. This study aimed to determine the seroprevalence of syphilis antibodies among blood donors at North Darfur State - Sudan, from 2017 to 2019

Methods: This retrospective descriptive analysis of consecutive blood donor's data records covering the period from January 2017 to December 2019 was performed. The medical and socio-demographic histories of the donors were registered in the logbook. The data was analyzed using IBM SPSS Statistical package version 20. Prevalence of syphilis was expressed as the number of sero-positive samples per year. Pearson Chi-squire $\left(\chi^{2}\right)$ test was used to evaluate the relationship between categorical variants. Ethical approval was obtained from Al Fashir University and Sudan Ministry of Health Ethical Review Boards.

Results: A total of 14819 blood donors were analyzed. The overall sero-prevalence of syphilis antibodies between 2017 and 2019 were 1927 (13\%). They were all adult's male, aged between 17 to 64 years, with a median age 29.5 years. The seroprevalence of syphilis was $10.9 \%$ in 2017 ; increased to $13 \%$ in 2018 and subsequently increased to $14.8 \%$ in 2019.
\end{abstract}

Conclusion: In This study it was observed that the seroprevalence of syphilis among blood donors continues high during the study period.

Keywords: Syphilis, North Darfur, blood donors, sero-prevalence, Sudan
Volume 9 Issue 2 - 202I

\author{
Nassreldeen Khalid Adam,' Mudathir Abdallah \\ Adam,' Mohamed Ahmed Ibrahim, ${ }^{2}$ Nahla \\ Ahmed Mohamed Abdelrahman, ${ }^{2}$ Marawa \\ Ahmed Mohammed Abd Erahman ${ }^{3}$ \\ 'Faculty of Medical Laboratory Science, Al Fashir University, \\ Sudan \\ ${ }^{2}$ Faculty of Medicine, Nile Valley University, Sudan \\ ${ }^{3}$ Dermatologist, Ministry of Health, Khartoum-Sudan
}

Correspondence: Dr. Mohammed Ahmed Ibrahim Ahmed, Assistant professor of Microbiology, Nile Valley University, Faculty of Medicine, Atbara, Sudan, Tel +2490122570655, Emailmohammedabukleewa@gmail.com

Received: April 25, 202I | Published: April 30, 202 |
Abbreviations: VNRBD, voluntary non-remunerated blood donation; TTIs, transfusion transmissible infections; HIV, human immunodeficiency virus; HBV, hepatitis B virus; $\mathrm{HCV}$, hepatitis $\mathrm{C}$ virus; Abs, antibodies; IBM, international business machines; ACBB, Alfashir central blood bank

\section{Background}

Syphilis is considered as global issue of health concern among people. The world Health Organization (WHO) estimated about one million people getting infected daily worldwide by one or more sexually transmitted diseases. ${ }^{1}$ Six millions of new cases of syphilis were determined annually among persons aged 15 to 49 years worldwide with high prevalence of fetal and neonatal deaths. ${ }^{2}$ Syphilis is a highly contagious chronic symptomatic or asymptomatic bacterial infection caused by Treponema pallidum, which is endemic in low income countries, but only occurs at low prevalence in middle and high income countries. Apart from its direct morbidity it increases the risk factors of co-infection by the Human Immunodeficiency Virus (HIV) and hepatitis. Moreover, syphilis may cause lifelong disease in children born to mothers infected. Furthermore, syphilis is a disease which, if not treated, will progress over the years through a series of clinical states, and may lead to irreversible cardiovascular and neurological complications. ${ }^{1-6}$ Treponema pallidum spirochetes transmitted via sexual intercourse, and congenitally, despite a refrigerated blood components are less infective for syphilis, transmissions through blood components still occur. So serological screening for syphilis and other infectious diseases is an important blood safety measure to avoid transfusion-transmitted infections (TTIs). ${ }^{3-6}$ An unsafe blood transfusion is very costly from both an economic and a human point of view, not only for the recipients themselves, but also for their families and their communities. 5

Syphilis is one of the infections transmitted through blood transfusion as shown by high antibodies detection in healthy African blood. Syphilis prevalence among blood donors in sub-Saharan African countries varies. In Nigeria, Mali, Tanzania, and Kenya its prevalence was $3.1 \%, 0.3 \%, 12.8 \%$, and $3.8 \%$ respectively. ${ }^{7,8}$ Eritrea and Ethiopia studies carried out by Siraj et al., ${ }^{9}$ and Tessema et al. ${ }^{10}$, documented the seroprevalence of syphilis among blood donors to be $0.3 \%$ and $1.3 \%$. In a survey conducted in Nigeria by Olokoba et al. ${ }^{11}$, Saudi Arabia by Elyamany et al. ${ }^{12}$, and in India by Chaudhary et al. ${ }^{13}$, the seroprevalence of syphilis were estimated to be $1.2 \%, 0.044 \%$ and $0.16 \%$.

Despite the well-recognized importance of studying syphilis epidemiology, published information about syphilis burden in Sudan is scanty. In North Darfur state, no published studies regarding this disease was available, except rare studies conducted in neighboring North Kordofan state, where $0.8 \%$ of seroprevalence of syphilis was documented by Elfaki et $a l,{ }^{6}$ and far Kassala state in the Eastern region $2.7 \%$ of syphilis prevalence was reported by Abdallah et al, ${ }^{14}$ in addition to Ahmed et al., ${ }^{15}$ reported the sero-prevalence of syphilis among blood donors was $5.4 \%$ in central Khartoum state. Therefore, the aim of this study was b to determine the seroprevalence of syphilis antibodies among blood donors at North Darfur State, Sudan, from 2017 to 2019 . 


\section{Methods}

\section{Study design}

A retrospective descriptive analysis of consecutive blood donor's data records covering the period from January 2017 to December 2019 was performed. The medical and socio-demographic histories of the donors such as: age, sex, region/zone of residence, type of donation and frequency of blood donation were registered in the logbook.

\section{Study area}

The data was extracted from Al Fashir Central Blood Bank (ACBB) logbook. ACBB is the only centre in Al Fashir City, (capital of Northern Darfur State), which provides TTI-tested blood and blood products for about 10 hospitals in the city. The centre has several sections. It comprises of waiting room, donor clinic section, laboratory sections: (TTI, Immunohematology), collection area and Component Preparation Sections). Donors at the facility are predominantly family members, friends, few Voluntary Non-Remunerated Blood Donation (VNRBD.) All the assays conducted by the TTI section to test for HIV, HBV, HCV and Syphilis were performed in strict compliance with existing national testing policies and guidelines.

\section{Study population}

A total of 14819 adults' blood donors were selected based on a preset criterion which particularized age (18-64 years), weight ( $>50 \mathrm{~kg})$ and medical history as per Sudan national blood transfusion protocol.

\section{Screening methods}

Serum from all blood donor's units was screened for the presence of treponemal antibodies using syphilis Abs rapid test cassette (fortress diagnostics/UK) by following the manufacturer's instructions. Confirmation of Treponema pallidum (TP) Abs rapid test results by using Kits for Enzyme-linked immunosorbent assay test (fortress diagnostics/UK).

\section{Statistical analysis}

Data retrieved from Al Fashir Central Blood Bank logbook was transferred to Excel spread sheet (Microsoft Corp). The data was subsequently cleaned, recoded and analyzed using IBM SPSS Statistical package version 20.0 (Armonk, New York, USA). Prevalence of syphilis was expressed as the number of sero-positive samples per year. Pearson Chi-squire $(\chi 2)$ test was used to evaluate the relationship between categorical variants. Chi-square trend test (Linear-by-Linear association) was applied to examine year-by-year variation in trends. A p - value $<0.05$ was considered statistically significant.

\section{Ethics approval}

Ethical clearance was obtained from Al Fashir University Research Ethical Committee board and Sudan Ministry of Health Research Ethical Committee. However, due to the nature of the study (retrospective records analysis) no participants were involved at any stage; informed consent was not obtained from the participants.

\section{Results}

A total of 14819 blood donors were analyzed. The overall seroprevalence of syphilis antibodies between 2017 and 2019 were 1927 (13\%). They were all adults' male, aged between 17 to 64 years, with a median age 29.5 years.

Concerning age, statistical association was observed between age groups and syphilis seroprevalence $(\mathrm{p}<0.001)$, accompanied with donors below 25 years had the highest seroprevalence than the others $3.4 \%$. Trends of syphilis seroprevalence: Significantly increasing trends of syphilis $(\mathrm{p}<0.001)$ seroprevalence were determined over the three years' study period. The seroprevalence of syphilis was $10.9 \%$ in 2017 ; increased to $13 \%$ in 2018 and subsequently increased to $14.8 \%$ in 2019 (Table 1). Regionally, donors from Al Malha region had the highest rate of seroprevalence $(23 \%)$ and donors from Serife region had the lowest syphilis seroprevalence cases $(1.9 \%),(\mathrm{p}<0.001)$ (Table 2).

Table I Seroprevalence of syphilis antibodies among blood donors. Al Fashir, 2017-20I8

\begin{tabular}{|c|c|c|c|c|c|c|}
\hline Variable & & Screened (frequency) & Percent (\%) & Syphilis positive (frequency) & Percent (\%) & p-value \\
\hline \multirow{5}{*}{ Age } & $<25$ & 4450 & 30 & 511 & 3.4 & \multirow{5}{*}{$<0.001$} \\
\hline & 25- 29 & 3942 & 27 & 332 & 2.2 & \\
\hline & 30- 39 & 2758 & 18 & 255 & I. 7 & \\
\hline & $35-39$ & 1955 & 13 & 376 & 2.5 & \\
\hline & $\geq 40$ & 1714 & 12 & 453 & 3.1 & \\
\hline \multirow{5}{*}{ Year } & 2017 & 4527 & & 493 & 10.9 & \multirow{5}{*}{$<0.001$} \\
\hline & 2018 & 4969 & - & 646 & 13 & \\
\hline & & & & & & \\
\hline & 2019 & 5323 & - & 789 & 14.8 & \\
\hline & & 14819 & - & 1927 & 13 & \\
\hline \multirow{3}{*}{ Syphilis } & Positive & 1927 & 13 & & - & \multirow{3}{*}{-} \\
\hline & & & & & & \\
\hline & Negative & 12892 & 87 & & - & \\
\hline Total & & 14819 & 100 & 1927 & 13 & \\
\hline
\end{tabular}


Table 2 Positivity of syphilis antibodies by region of residence of the donors

\begin{tabular}{llll}
\hline Region of Residence & Donors (frequency) & Positive Anti TP (frequency) & Percent (\%) \\
\hline Algadarif & 9 & 0 & 0 \\
Algenanh & 4 & 0 & 0 \\
Alkoma & 131 & 13 & 9.9 \\
Alleit & 1 & 0 & 0 \\
AlMalha & 104 & 24 & 23 \\
Alobeid & 7 & 0 & 0 \\
Altwasha & 7 & 0 & 0 \\
El Fashir & 11413 & 1329 & 11.6 \\
IDPs camps & 1945 & 417 & 21.4 \\
Kabkabia & 21 & & 0 \\
Kalamendo & 89 & 24 & 27 \\
Khartoum & 204 & 9 & 4.4 \\
Kutoum & 247 & 17 & 6.9 \\
Madany & 4 & 0 & 0 \\
Malit & 253 & 46 & 18 \\
Nyala & 51 & 3 & 5.9 \\
Serife & 51 & 1 & 1.9 \\
Tawila & 132 & 8 & 6 \\
Umkadada & 94 & 1927 & 27 \\
Daralsalam & 52 & & 13 \\
Total & 14819 & 11.2 \\
\hline
\end{tabular}

\section{Discussion}

The results of this study determined the prevalence of syphilis antibodies in blood units donated in Al Fashir Central Blood Bank of north Darfur state from 2017 to 2019. In our study all the donors were males. The predominance of male donors could partially be linked to physiological differences between men and women, cultural misconception of the society, pregnancy, breastfeeding, and higher prevalence of iron deficiency anemia among women, in addition to the popular perception that men are healthier than women may increase the number of male blood donors.

The majority of age groups donated blood contributed in this study was those below 25 years $(30 \%)$, which were closely related to the figures published by the world health organization (WHO), $45 \%$ of donors were aged 25 years or less. ${ }^{16}$ So, a lot of awareness creation activity targeting younger age groups is needed. The overall prevalence of syphilis antibodies in this study among blood donor units in Al Fashir Central Blood Bank was (13\%). This is being higher than $(0.8 \%)$, which documented in neighboring El Obeid, northern Kordofan by El faki et al. ${ }^{6}$ Progressively, high seroprevalence of syphilis antibodies (23.5\%) were detected in south western Kordofan state, Sudan by Elagib et al. ${ }^{17}$, among blood donors. This high seroprevalence is related to the lack of health education in addition to political conflux which lead to IDPs.

Steady low (8\%) and $(2.5 \%)$ seroprevalence of syphilis antibodies were determined among pregnant ladies and blood donated units, in Tri-capital Khartoum and Kassala states, Sudan by Nagi and his colleagues, and Abdallah et al respectively. ${ }^{15,18}$ This variation in seroprevalence of syphilis antibodies among different societies in Sudan could refer to the diversity in the number of screened blood donated units. In neighboring Eritrea, a low seroprevalence of syphilis antibodies $(0.6 \%)$ and $(7.2 \%)$ were reported in Asmara and Gash Barka by Siraj et al., ${ }^{9}$ and Keleta et al., ${ }^{19}$ respectively. Variety of syphilis antibodies seroprevalence were reported in a number of African countries by Quintas et al, ${ }^{4}$ Tessema et al, ${ }^{10}$ Olokoba et al, ${ }^{11}$ Yambasu et al., ${ }^{20}$ and Adjei et al., ${ }^{21}$ in Angola, Ethiopia, Nigeria, Sierra Leone and Ghana were $20 \%, 1.3 \%, 1.2 \%, 0.8 \%$ and $7.5 \%$ respectively. A low seroprevalence of syphilis antibodies were detected in middle and high income countries, such as: Saudi Arabia, Israel, Pakistan, India and Italy, among them the seroprevalence were $(0.025 \%),(0.05 \%)$, $(0.35 \%)$, and $(0.031 \%)$ in studies performed by El yamany et al, Vera et al, Siddiqui et al, Patel et al, and Cogorno et al respectively. ${ }^{12,22-24}$

\section{Conclusion}

In This study it was observed that the sero-prevalence of syphilis among blood donors continues high during the study period, despite the absence of published estimates of syphilis seroprevalence by Sudan Ministry of Health during the mentioned period. It is important to raise the awareness campaigns and encourage the use of condoms among this key population group to intensify campaigns for the prevention and control of syphilis.

\section{Acknowledgments}

We acknowledge all the staff members of Al Fashir Central Blood Bank (ACBB) for their cooperation during data collection. 


\section{Conflicts of interest}

Authors declare that there is no conflict of interest.

\section{References}

1. Quintas E, Cogle AC, Dias C, et al. Prevalence of syphilis in blood donors in angola from 2011 to 2016. Clin Med Rep. 2018;2(1):1-4.

2. Kojima N, Klausner JD. An Update on the Global Epidemiology of Syphilis. Curr Epidemiol Rep. 2018;5(1):24-38.

3. Vera L, Milka D, Nurith S, et al. Prevalence and Incidence of Syphilis among Volunteer Blood Donors in Israel. Journal of Blood Transfusion. 2014;2014:154048.

4. Baião AM, Kupek E, Petry A. Syphilis Seroprevalence estimates of Santa Catarina blood donors in 2010. Revista Sociedade Brasileira de Medicina Tropical.2014;47(2):179-185.

5. Liu S, Luo L, Xi G, et al. Seroprevalence and risk factors on Syphilis among blood donors in Chengdu, China,from 2005 to 2017. BMC Infect Dis. 2019;19:509.

6. Elfaki AMH, Agab Aldour AA, Elsheikh NMH. Ser-prevalence of immunodeficiency virus, hepatitis B and C and Syphilis among blood donors at ElObeid Teaching Hospital, west Sudan. Sudan JMS. 2008;3(4):333-338.

7. Jary 1 A, Dienta S, Leducq V, et al. Seroprevalence and risk factors for HIV, HCV, HBV and syphilis among blood donors in Mali. BMC Infectious Diseases. 2019;19(1):1064.

8. Mavenyengwa1 RT, Mukesil M, Israel Chipare I, et al. Prevalence of human immunodeficiency virus syphilis, hepatitis B and $\mathrm{C}$ in blood donations in Namibia. BMC Public Health. 2014;14:424.

9. Siraj N, Achila OO, Issac J, et al. Serprovalence of transfusiontransmissible infections among blood donors at National Blood Transfusion Service, Eritrea: a seven-years retrospective study. $B M C$ Infectious Diseases. 2018;18(1):264.

10. Tessema B, Yismaw G, Kassu A, et al. Seroprevalence of HIV, HBV, $\mathrm{HCV}$ and Syphilis infections among blood donors at Gondar University Teaching Hospital, Northwset Ethiopia: declining trends over a period of five years. BMC Infectious Diseases. 2010;10:111.

11. Olokoba AB, Olokoba LB, Salawu FK, et al. Syphilis in Voluntary Blood Donors in North-Eastern, Nigeria. European Journal of Scientific Research. 2009;31(3):335-338.

12. Elyamany G, Alamro M, Pereiva WC, et al. Prevalence of Syphilis among Blood and Stem Cell Donors in Saudi Arabia: An Institutional Experience. Electronic Physician. 2016;8(8):2747-2751.
13. Chaudhary V, Agrawal VK, Sexena SK, et al. Seroprevalence of common transfusion transmissible infections among blood donors in western Uttar Pradesh, India. Int J Med Sci Public Health. 2014;3(11):1381-1384.

14. Abdallah TM, Ali AA. Sero-prevalence of transfusion-transmissible infectious diseases among blood donors in Kassala, eastern Sudan. Journal of Medicine and Medical Science. 2011;2(11).

15. Ahmed NO, Omer EO and Mohamed MA. Sero-prevalence of Transfusion Transmissible Infections among Blood Donors in Khartoum Central Sudan. European Academic Research. 2016;IV(3):2233-2246.

16. Teo KS, Saparudin MS, Zain Z, et al. Transfusion transmissible infections in Brunei Darussalam: a blood donor study. Brunei Int Med J. 2011;7(6):321-327.

17. Elagib AA, Abdelmagid MA. Seroprevalence of syphilis among Blood Donors in South Western Sudan; 2014.

18. Nagi AM, Wedaat Allah HA, Khalil OM. Seroprevalence of syphilis Among Pregnant Women in the Tri-capital, Khartoum, Sudan. Res $J$ Medicine \& Med Sci. 2008;3(1):48-52.

19. Keleta YT, Achila OO, Haile AW, et al. Seroprevalence of Antibodies to syphilis among Blood donors in Gash Barka Zonal Blood Transfusion Centre, Barenty, Eritrea, 2014 through 2017. BMC Hematology. 2019;19:5.

20. Yambasu EE, Reid A, Owiti P, et al. Hidden dangers-prevalence of blood borne pathogens, hepatitis B, C, HIV and Syphilis, among blood donors in Sierra Leone in 2016: Opportunities for important: a retrospective, cross-sectional study. Pan African Medical Journal. 2018;30:44.

21. Adjei AA, Kudzi W, Armah H, et al. Prevalence of Antibodies to syphilis among Blood Donors in Africa, Ghana. Jpn J Infect Dis. 2003;56(4):165-167.

22. Siddiqui FM, Siddiqui N, Oluwatayo O, et al. Prevalence of Transfusmissible Infections among Voluntary Blood Donors in Tertiary Health-Care Facility in Islamabad, Pakistan. J Clin Trials. 2019;9:383.

23. Patel S, Popat C, Mazumdar V, et al. Seroprevalence of hiv, hbv, hcv and syphilis in blood donors at a tertiary hospital (blood bank) in vadodara. International Journal of Medicine Science and Public Health. 2013;2(3):747-750.

24. Cogorno F, Drago F, Ciccarese G, et al. Prevalence of syphilis among voluntary blood donors in Liguria region (Italy) from 2009 to 2013. International Journal of Infectious Diseases. 2014;28:45-46. 